\title{
Exploration and Practice Path of Applied Undergraduate Students' Innovative Ability Training
}

\author{
Zhang Lin \\ Department of Computer Information and Technology \\ Xi'an University of Technological Information \\ XI'AN, China \\ e-mail: zhanglin@xatu.edu.cn
}

\author{
Xue Shulei \\ Xi'an University of Technological Information \\ Xi'an Technological University \\ XI'AN, China \\ e-mail: xueshulei@xatu.edu.cn
}

\begin{abstract}
Innovation ability is a basic characteristic of excellent engineers. The paper focuses on the exploration of the students' innovative ability training in the application-oriented universities, mainly discussing the structure of undergraduates' innovative ability, the innovative curriculum resources, the task-driven self-organization learning, the innovative practice education system, and the innovation education ecological environment, etc. The innovation course is as the starting point of innovation ability training, and around the process of student innovation ability to build innovative practice education system, and gradually improve the innovative ecological environment, a bottom-up application undergraduate innovation ability training path will be put forward by the example analysis.
\end{abstract}

Keywords-Applied Undergraduate; Innovation Ability; Innovative Education; Training Path

\section{INTRODUCTION}

Innovative personnel training are to cultivate talents with innovative awareness, innovative thinking and innovation ability. Innovative awareness is the goal and motivation to realize the invention. Innovative thinking is the advanced and complex cognitive ability to have innovative ideas, theories, methods and designs. The innovative ability is practical ability to transform innovative ideas, theories, methods and innovative designs into the actual spiritual or material products [1]. Application-based undergraduates should be able to innovate in the design, marketing and service or project development, operation and maintenance of products in the frontier, and become excellent application innovation engineers [2]. Innovative personnel's training is a systematic project that demonstrates the feasibility of the training system from the abstract level. However, in the process of implementation, the macro-training program is difficult to implement due to the complexity of the problem, the difference between time and space, the difference between the training environment and the training object. With the cultivation of innovation ability as the starting point, it is feasible to cultivate innovative talents among application undergraduates, and to construct an innovative ability training path based on educational practice.

This paper is about the research of training path for applied undergraduate students' innovative ability, mainly focusing on innovative curriculum resources, task-driven self-organization learning style, innovation and practice education system, innovation education ecological environment and so on. Through the example analysis of innovation ability training effect, it sums up a bottom-up training path for application of undergraduate innovation ability.

\section{ANALYSIS ON THE STRUCTURE OF INNOVATIVE ABILITY OF APPLIED UNDERGRADUATES}

Innovation is an important force to promote the development of a nation, but also an important force to promote the development of human society as a whole. Facing the new economic situation changes and characteristics to cultivate innovative talents is to lay a solid foundation of human resources for the construction of innovative countries. Innovative ability refers to the ability to carry out innovative and practicing activities through based on the integration of existing resources, through innovative thinking activities to identify and solve new problems creatively. The application of undergraduate students' innovative ability is reflected in the discovery of new problems in engineering practice, the discovery of new needs according to economic and social development needs, and the design and development of new products, new technologies and the ability to achieve new project objectives through creative engineering practice activities. Innovation ability is a complex ability, mainly by the knowledge structure, innovation consciousness, innovative thinking, innovative skills and innovative quality and other factors interact with the formation of the comprehensive ability [2].

\section{A. knowledge structure}

Reasonable knowledge structure is the basis of talent growth. Application-oriented talents have different characteristics from academic research-oriented talents and practical talents, and should highlight the industry, application and sociality [3]. By the application of undergraduate students knowledge structure, including solid professional theoretical knowledge, rich practical skills, master the relevant disciplines and industry trends, with relevant disciplines and interdisciplinary basic knowledge, have a certain knowledge of humanities and social sciences. 
There are three basic dimensions for engineering students: science to theoretical exploration, engineering to technology research, application to application. Application-oriented undergraduate innovation activities are first from the application level, and constantly improve the knowledge structure in the continuous application of technological innovation activities. In the activities of innovation, they should not only master the engineering principles, engineering and technology application knowledge, understanding of new technologies, new tools and technology development status and trends, but also have a broad knowledge of vision, identify problems and propose solutions.

\section{B. Innovation awareness}

Innovative consciousness is a conscious and active attitude towards innovation on the basis of fully understanding the importance of innovation. The formation of the sense of innovation on the one hand is related to the value orientation, on the other hand is about the human instinct demand. From the perspective of the value orientation, the innovation consciousness has the lofty ideals that contribute to the civilization and progress of mankind and the devotion to the development of science and technology. From the instinctive demand, the innovation consciousness is expressed as hobbies, knowledge and desire, curiosity, and the desire to create inventions. Innovation is the driving force for innovative ideas and practical activities is the premise and conditions for generating innovative thinking.

To form a sense of innovation, application - oriented undergraduates should make great efforts from the values and practice. As to values, innovation awareness must be established through long-term, unremitting outlook on life and the cultivation of values. As to practice, it should cultivate students 'hobbies, enhance curiosity, and fully mobilize students' curiosity about new things through the theory and practice teaching design. In the innovation education, the cultivation of innovation consciousness should mainly rely on subject of teaching in current teaching system.

\section{Innovative thinking}

Based on the knowledge and experience that the innovative talents have already grasped, and under the strong innovation consciousness, innovative thinking is a thinking process to discover or raise problems from the different aspects by processing, analyzing and refining the various kinds of information; to analyze the interrelationships among many factors and grasp the main contradictions of intricate problems; and to proposing a complex thinking process, a path, or a method to solve the problem [2].

The cultivation of applied undergraduate students' innovative thinking should include the content of thinking and the form of thinking. Thinking content for the students is to master and understand the various types of knowledge, which reflecting the basic level of students' awareness. The form of thinking embodies the different ways in which students express their minds. Innovative thinking is not a form of thinking, but a comprehensive reflection of a variety of forms of thinking. Training students to master a variety of ways of thinking, can help students to carry out innovative thinking activities.

\section{Innovative skills}

Innovative skills are the ability to translate the results of innovative thinking into innovative results, specifically for practical ability. There is a difference between innovative skills and general practice. Innovation ability is a practical ability driven by the innovation consciousness to make full use of innovative thinking to form the results of innovative thinking, and to complete the transformation in the continuous exploration.

Application-oriented undergraduates' innovative skill training should emphasize the training of innovative practical ability. Besides the basic theory and practical knowledge, students should master the relevant new tools, new technologies and their application methods. Innovative skills are an important guarantee for innovative results to be achieved. The process to explore practice constantly with innovative skills is a creative practice and the external performance of innovation.

\section{E. innovative quality}

Innovative literacy is the ability and quality to complete the innovation activities, but also the basis for the continuous improvement of innovation ability. Innovative literacy is manifested in the ability of information acquisition, knowledge renewal and lifelong learning, teamwork and communication skills, scientific and cultural literacy, physical and psychological quality. These capabilities and qualities can facilitate the efficient and sustained innovation.

The cultivation of applied undergraduates' innovative literacy should be combined with extracurricular class. Some of the students' knowledge, skills and qualities are acquired and improved in extracurricular activities. The formation of extracurricular activities on students' abilities can often play a role in classroom teaching [3]. Because of the social nature of their work, the application talents need strong social communication ability and good personality quality in order to show their advantages. The cultivation of innovative literacy is of great importance and necessity to cultivate the innovation ability of applied undergraduates.

\section{APPLiCATION OF UndergraduAte StUdENTS' INNOVATIVE ABILITY}

Personnel training generally include teaching activities, practical activities, campus culture and other extracurricular education activities. Application-oriented undergraduate talent training, which includes theoretical teaching, practice teaching and quality development system, focuses on harmonious development with knowledge, ability and quality. However, in the process of implementation, it is difficult to change the existing training system into the ideal state which adapt to the innovation education. The cultivation of students' innovation ability is always carried out in the current training system step by step. Based on the previous teaching experience, the author tries to explore the construction of the innovation ability training path creatively 
from the construction of innovative curriculum resources, the innovation and practice education system, the task - driven self - organization learning mode and the ecological environment in innovation education.

\section{A. Innovative curriculum resources construction}

Innovative curriculum resources mainly include curriculum system, teaching content and teachers. The first two elements determine the structure and connotation of the knowledge, ability and quality of the personnel training objects. Teachers are the direct commitment of teaching, and high-quality teachers are guarantee to promote innovative education. Application-oriented undergraduates training is positioned as the application of capacity-building, emphasizing capacity-oriented curriculum system and teaching content. The establishment of innovative curriculum in the traditional curriculum system is an important work of the reform of the curriculum system. Through the innovation course, the theory and practice teaching are integrated to execute the comprehensive cultivation of knowledge, ability and quality.

The creation of innovative curriculum is the starting point of building innovative educational resources. Innovative curriculum has the characteristics of novel content, knowledge and skills for business needs, in which the theory and practice are closely tied, and practice is overweight, which attracts students easily [4]. It's a good start that it inspires the student's interest and they will achieve significant learning effect. Facing the computer science undergraduate, it opened up courses about mobile application development as an extension of the basic disciplines of computer science courses to strengthen the application of student engineering and technical training. The course covers the development of Android platform application software, so that students have the basic theory and development skills of mobile application development.

There are still some difficulties in the early years of innovative curriculum. The reason of weak teacher is that it lack of teachers who can undertake innovative courses, and higher requirements to the teachers of the new technology. The input of new experimental equipment requires amounts of money and time. It's also a problem that teachers have to face the shortage of laboratory's equipment. Usually, new technology is short of technical introductions, which is a problem that teachers need to overcome. From experiences of starting, these problems can be gradually solved during the process of teaching implement. Relevant technical reserves and future prospects are the main determinants of the creation of innovative courses.

Innovative courses, new technologies and new needs of the market closely, which is the integration of traditional curriculum system and innovative education curriculum system. The innovative curriculum links the student's professional knowledge with practical problems, improves the knowledge structure in the process of solving the problem, enhances the sense of innovation, trains the innovative thinking and improves the innovative skills. Through innovative courses, it can gradually improve the curriculum system for cultivating the ability of innovation.

\section{B. to build innovative practice education system}

Practical teaching is an important way to cultivate students' professional ability, comprehensive ability and innovation ability. Application-oriented undergraduate students training should focus on practical skills and innovative skills. Practical teaching is an important part of cultivating innovation ability. It is necessary to strengthen the traditional practice teaching, such as experiment, practice and graduation design. And construct innovative practice education system is an important way to cultivate innovation ability.

The essence of innovation practice education is the education and teaching activity which makes the students as the main body of innovative practical activities, and teachers as the guide or tutor of innovative practical activities [2]. Traditional practice teaching resources should apply innovative thinking transformation, and use experiential learning method to design interesting, complete, modular, practical teaching project resources [5]. The education and teaching activities in the innovation and practice education system are mainly composed of innovative experiments, innovative projects, innovation competition, scientific research projects and enterprise training.

The teaching activity is the main practice teaching content in the innovation and practice education system. In order to cooperate with the teaching activities smoothly, the construction of practical teaching resources is the foundation of the cultivation of practical ability. To promote the construction of traditional curriculum experimental resources, with simulation, simulation of technical means to achieve innovative curriculum experimental resources, in the development process to gradually improve the innovation and practice education system. To highlight the innovative and practical education system of comprehensive and systematic, the school integration of practical teaching resources, the establishment of engineering training center, the school factory, enterprise production practice base.

\section{C. the task-driven self-organization learning}

Chinese and Western innovative education emphasizes "learning in the creation" or "based on the creation of learning", that this is the learners really need to learn; advocate a specific task as the center, so that students can complete the task in the process to learn, so as to cultivate students to solve practical problems; advocate in the implementation of the process of entrepreneurship through collaboration, communication and sharing of deepening the meaning of knowledge construction [1].

The task-centered, in the creation of learning, collaboration, communication and sharing is a prominent feature of innovative education. Application-oriented undergraduate students innovative ability training, to a specific task-driven, the implementation of student selforganization learning. The task can make the goal of innovation activities more clearly, but also reflects the teacher's guiding role. Self-organization learning highlights the student's dominant position, strengthens the collaboration, communication and sharing among students, and makes the students the creator of knowledge. 


\section{Innovative education ecological environment}

Innovative education based on professional education, to build innovative education Ecological environment should be to build a professional education ecological environment as a specific implementation object. Professional ecological environment, including the construction of professional areas of cultural system, to create a professional education system, an organic combination of teaching and management of the educational mechanism, the standardization of basic teaching process, and the implementation of student development plans, it covers students' learning, daily life and personal development from all aspects. Constructing a completely professional ecological environment needs to give full play to professional teachers and student management of the synergies. The professional ecological environment is the sum of all the teaching and learning relations, covering the professional field, teaching process and education process. It is not only a reflection in the professional training program, but also in the campus culture, professional culture, class culture, dormitory culture and other aspects, which are linked closely. The professional ecological environment constructed from culture, professional and personal development is a good ecological environment for implementing innovative education.

\section{ANALYSES ON THE EFFECT OF INNOVATIVE ABILITY Cultivation}

Innovative competition is an effective practice of innovation and practice, which is an important way to cultivate students' innovative ability. Now this paper will analyze the training efforts of innovation with the combination of the opening innovation courses of mobile application and the related competition.

In 2010, it joined the Android academic cooperation program, preparing courses of Android platform mobile application development. The first half of 2011, software engineering professional officially started in the Grade 2008. After the construction, our school was selected as Google Android talent training demonstration base, "3G mobile phone software development" course was identified as Android certification courses, approved by Google school to build practical courses, successful reporting and funded student innovation project 4, won the 2015 Google Faculty Award.

In 2011 ,the second Android application development Chinese college students challenge was held, from more than 300 colleges and universities, more than 1380 participation teams submitted entries. 16 students participated in my school, they submitted 18 works, accounting for $10.3 \%$ of the number of works. 117 people account for $13.7 \%$ participate the innovation course. National Finals our school won four outstanding awards. 2012 third Android application development Chinese college students challenge, the national entries of about 2000 works. It have a total of 17 students participating in the school, submitted 15 works, accounting for $8.4 \%$ of the division works. Participate in the number of innovative courses 46 , the proportion of $37 \%$.
2010 - 2011, Android application development in China has just emerged, the innovative courses to improve the enthusiasm of students to participate in innovation competition. Through the competition, students can improve their own knowledge structure; in the process of continuous optimization of the project program to train innovative thinking ability, the program into a APP greatly enhance the students' innovative skills.

Mobile application development courses is as the starting point, followed by our school and Google and other enterprises to establish relations of cooperation, to promote the school and enterprise to development practical courses, student innovation projects, innovation competition, practice education system, and professional ecological environment.

\section{SUMMARY}

There are many schemes for the organization and implementation of the innovation ability of applied undergraduates. It explores the path of innovation ability adapting to our own characteristics on the basis of the existing innovative educational achievements. The school should have a profound understanding of the connotation of innovation education, and analyze the characteristics and innovation ability of applied undergraduate students. Integration of existing educational resources and training system, which bases on the existing educational foundation to implement innovative education is necessary It is unreasonable to leave the traditional education system independently to carry out innovative education. Innovation curriculum to adapt to economic and social development needs, as the implementation of innovation ability training entry point, guide students in the continuous creation of selforganized learning, training innovative thinking, enhance the innovative skills, around the process of student innovation ability to build innovative practice education system, and gradually improve the innovative ecological environment to ensure that innovation can develop continuity, in order to build a bottom-up innovation ability training path.

\section{ACKNOWLEDGMENT}

Scientific Research Program Funded by Shaanxi Provincial Education Department (Program No.2013JK1177)

Teaching Reform Research Project Supported by Xi'an University of Technological Information (No. YJ1419)

\section{REFERENCES}

[1] He Kekang. On Maker Education and Innovation Education[J]. Education and Vocation, 2016,37 (04): 12-24 +40.

[2] Lin Jian. On Outstanding Engineer's Innovation Ability Training[J]. Research in Higher Education of Engineering, 2012, (05): 1-17. [J].

[3] Zeng Qiuju.Application of Undergraduate Innovative Talents Training Strategy [J]. China Adult Education, 2016, (23): 73-76.

[4] Zhang Lin, Rong Xiaofeng, Shen Hong. Mobile Application Development Course Construction and Teaching Model Exploration [J]. Computer Education, 2012, (No. 14): 95-99.

[5] Yang Xianmin. Construction of Maker's Courses: connotation, characteristics and design framework $[\mathrm{J}]$. Journal of Distance Educationl, 2016,35 (03): 3-14. 